\title{
ANALYSIS OF DRYING PROCESS OF SEA BUCKTHORN (HIPPOPHAE RHAMNOIDES L.) BERRIES
}

Egidijus Zvicevicius, Ausra Cipliene, Algirdas Raila, Aurelija Paulauskiene

Vytautas Magnus University, Lithuania

egidijus.zvicevicius@asu.lt, ausra.cipliene@asu.lt, algirdas.raila@asu.lt, aurelija.paulauskiene@vdu.lt

\begin{abstract}
In 2020, 2540 hectars of sea buckthorn berries were declared in Lithuania. In recent years, their growing areas have decreased, but sea buckthorn is still one of the most cultivated berry bushes in Lithuania. Sea buckthorn berries are rich in biologically valuable substances: ascorbic acid, vitamin $\mathrm{B}_{1}, \mathrm{~B}_{2}, \mathrm{~B}_{6}, \mathrm{E}$, F, carotene, tannins, fat, iron, manganese, etc. Their content in berries depends on the growing conditions, variety and other factors. But in any case, sea buckthorn berries and their products are a reliable preventive and curative measure against avitaminosis. Sea buckthorn berries are also rich in moisture. Their moisture reaches $86.4 \pm 0.37 \%$. This creates favorable conditions for the quality of berries to decline and for molds and insects to develop. In addition, the berries are covered with a thick skin. It accounts for more than $7.5 \%$ berry mass and complicates the drying process of berries. When drying with active ventilation and blowing at a temperature of $33.0 \pm 2.3{ }^{\circ} \mathrm{C}$ and $54.9 \pm 4.6 \%$ relative humidity dryer - the longest dried fresh sea buckthorn berries. From $86.4 \pm 0.37 \%$ to $13.6 \pm 0.31 \%$ moisture they dried in 891 hours. Therefore, in practice, various technological means are used to activate the moisture exchange between the berries and the dryer. The article evaluates the effect of thermal treatment of berries on the drying process. Studies were performed using both fresh and frozen sea buckthorn berries. High-temperature treatment of sea buckthorn berries has been found to be an effective means of shortening the drying process, especially for fresh berries: the drying time of fresh berries treated with high-temperature decreased by 6.06 times, and that of frozen berries - by 1.31 times.
\end{abstract}

Keywords: sea buckthorn, berries, drying, drying time, thermal treatment.

\section{Introduction}

Nowadays, there has been an increasing focus on products with high biological and nutritional value. Siro I et.al (2008) say that trade in functional foods is growing every year from $15 \%$ up to $20 \%$ [1]. In addition, the COVID-19 pandemic that began in 2019 has led to an even greater interest in biologically valuable products enhancing immunity [2].

Sea buckthorn is one of the most significant super foods in the world and is widely grown in Asia, Europe and Canada [3; 4]. Buckthorn products obtained from fruit, leaves or seeds are widely used in food, animal feed, cosmetics, and the pharmaceutical industry. All parts of sea buckthorn are valuable in biologically valuable substances, but the most important part of the plant is the fruit. These are spherical or ovoid shape stone fruits, which lengths and widths variation is from 4 to $5 \mathrm{~mm}$ and from 3 to $10 \mathrm{~mm}$, respectively. The colour of ripe fruit can be whitish yellow, yellow, light orange, reddish orange, or even brown [5-7]. Higher amounts of carotenoids are found in reddish-orange fruits.

The content of biologically active substances in sea buckthorn fruits depends on the biological characteristics of the variety, age, growing and meteorological conditions, plant care, fruit ripeness and harvest time [3;5-8]. Sea buckthorn fruits contain a large complex of vitamins, the most important of which is vitamin $\mathrm{C}$, which can be up to $210.0 \mathrm{mg} \%$ from the dry mass $[3 ; 5 ; 9]$. It is stated that sea buckthorn fruits contain 4 to 100 times more vitamin $C$ than many other fruits or vegetables [10]. In addition, they are rich in other active ingredients, i.e. vitamin $\mathrm{P}$ - from $250.0 \mathrm{mg} \%$, tocopherols (vitamin E) - from 4.0 to $18.0 \mathrm{mg} \%$, vitamin $\mathrm{B}_{1}$ - up to $0.04 \mathrm{mg} \%$, vitamin $\mathrm{B}_{2}-$ up to $0.06 \mathrm{mg} \%$, vitamin $\mathrm{PP}$ up to $0.90 \mathrm{mg} \%$, vitamin $\mathrm{K}$ - up to $1.3 \mathrm{mg} \%$, folic acid - up to $0.80 \mathrm{mg} \%$; fats $-2.5-8.0 \%$ (oleic, stearic, palmitic, linoleic, linolenic acids), carotenoids - up to $170.0 \mathrm{mg} \%$ (average $-60.0 \mathrm{mg} \%$ ), saccharides 2.1-5.2\%, organic acids (lemon, malic, tartaric, butter) $-1.0-3.9 \%$, yeast - up to $0.7 \%$, etc.

Although sea buckthorn berries are valuable and widely used, their preparation and processing present many challenges. In industrial production, priority is often given to dried produce, due to lower production biological activity, simpler storage, and lower product weight. However, sea buckthorn fruits are a difficult object to dry. Freeze-drying (lyophilization) can be used to dry sea buckthorn fruits while maintaining their high quality, but the production cost of the product is about 4 times higher than drying by convection with hot air $[11 ; 12]$. George S.D. ST., Cenkoeski S. (2009) studied the drying process of sea buckthorn pulp cake (pulp/peel) under active ventilation at different dryer temperatures and relative humidities, i.e. $50{ }^{\circ} \mathrm{C}, 30.6 \%$ and $58.7 \% \mathrm{RH}, 60^{\circ} \mathrm{C}, 24.4 \%$ and $57 \% \mathrm{RH}$ and $70{ }^{\circ} \mathrm{C}, 20.8 \%$ and $57 \% \mathrm{RH}$. 
Their studies showed that total carotenoid and phytosterol concentrations remained relatively stable. The lowest color change was achieved at $60{ }^{\circ} \mathrm{C}$ and $24.4 \% \mathrm{RH}$. However, in all cases studied, the highest colour change was obtained at a higher relative humidity of the dryer [4]. Drying tests were performed by drying sea buckthorn fruits by convection at $50{ }^{\circ} \mathrm{C}$ and $60{ }^{\circ} \mathrm{C}$ at $1 \mathrm{~m} \cdot \mathrm{s}^{-1}$ and by vacuum drying at $4 \mathrm{~Pa}$ under vacuum at $20^{\circ} \mathrm{C}$ or $50^{\circ} \mathrm{C}$. It has been found that drying kinetics increase at higher temperatures. It has also been observed that a small decrease in bioactive compounds, such as vitamin $\mathrm{E}$, is obtained at higher temperatures [12].

However, there is still a lack of innovative convective drying technologies that would facilitate the drying process of sea buckthorn berries, which is complicated by the presence of thick waxy skin that retains moisture inside the berries. The aim of these studies was to evaluate different thermal treatment methods for berries drying process.

The aim is to evaluate the effect of thermal treatment technology on the drying process and kinetics of sea buckthorn (Hippophae rhamnoides L.) berries.

\section{Materials and methods}

The drying study of sea buckthorn berries was carried out at the Laboratory of Biomass treatment, logistics and solid fuel processes, at the Institute of Energy and Biotechnology Engineering, Vytautas Magnus University, Academy of Agriculture. A special drying system (Fig. 1) was used during the research, which consists of a dryer preparation equipment and a drying stand. The drying agent preparation equipment is designed to prepare the drying agent with the desired parameters. It consists of a flow air conditioning system and a conditioned air reservoir-collector. The circulating air flow is continuously conditioned, maintaining the desired temperature and relative humidity of the prepared drying agent. From reservoir-collector the drying agent is directed by a fan to the drying stand. At that time, the drying agent leaking from the drying agent preparation equipment is compensated with ambient air, which is sucked in through the suction opening and enters the air flow circulating inside.

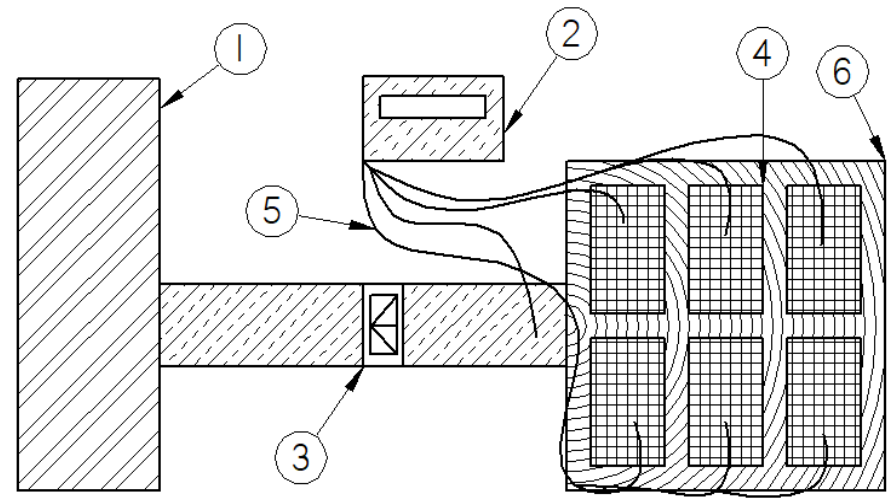

Fig. 1. Schematic diagram of the drying system: 1 - drying agent preparation equipment; 2 - data logger "Almemo 3290"; 3 - fan; 4 - ventilated containers for berry drying; 5 - temperature and relative humidity sensors; 6 - drying stand

The drying stand consists of adryer spreader (constant static pressure chamber) and drying areas. From the dryer preparation equipment, the drying agent first enters a constant static pressure chamber, in which it is evenly divided over the entire drying zone. In order to distribute the drying agent more evenly, a layer of fine stones is formed above the constant static pressure chamber, through which their drying agent enters the drying zone with ventilated containers. These are $290 \times 200 \times 40 \mathrm{~mm}$ wooden boxes with mesh bottom. A plastic net with $2 \times 2 \mathrm{~mm}$ meshes was used to install the net bottom.

Fresh (unfrozen) and frozen sea buckthorn berries were used in comparative studies of drying technologies. They were divided into six ventilated containers of $1.4 \mathrm{~kg}$ each. Two ventilated containers were filled with fresh berries, which were picked from twigs by hand. The other two containers with fresh berries, but before drying they were treated at high temperature: fresh sea buckthorn berries, picked from twigs by hand, were stored at $90^{\circ} \mathrm{C}$ in a MEMMERT UF450 oven for 1 hour. Two more ventilation containers are filled with frozen berries: first of all, sea buckthorn berries were frozen up to $-18{ }^{\circ} \mathrm{C}$ temperature, then separated from the twigs and then began to dry without pre-thawing. 
Sea buckthorn berries were ventilated with drying agent at a temperature of $33.0 \pm 2.3{ }^{\circ} \mathrm{C}$ and a relative humidity of $54.9 \pm 4.6 \%$. Parameters of drying agent were recorded using ALMEMO thermocouples (ZA 9020-FS) and temperature-relative humidity sensors (ZA D9462AKL10). Measurements of drying agent temperature and relative humidity were performed in a constant static pressure chamber and in each ventilated container in a berry layer. Parameters of drying agent were recorded every 5 minutes and stored in an ALMEMO 3290 data logger. Subsequently, the measurement data were transferred from the storage device to the computer and analyzed.

Ventilation intensity control of sea buckthorn berries was performed every 1-3 days: with wing anemometer FVA915-SMA1 were measured the speed of the dryer passing through the dried berries. Depending on the measurement results, the fan motor speed was changed, and the comparative dryer flow was calculated:

$$
L_{l y g}=\frac{3600 \cdot F \cdot v}{M},
$$

where $L_{l y g}-$ comparative dryer flow (comparative ventilation intensity), $\mathrm{m}^{3} \cdot(\mathrm{kg} \cdot \mathrm{h})^{-1}$;

$F$ - cross-sectional area of the ventilated box, $\mathrm{m}^{2}$;

$v$ - average velocity of air passing through the sea buckthorn berry layer, $\mathrm{m} \cdot \mathrm{s}^{-1}$;

$M$ - mass of sea buckthorn berries placed in a ventilated container, $\mathrm{kg}$.

The mass of sea buckthorn berries was also recorded in experimental studies. Ventilated containers with berries were periodically removed from the drying bench, weighed on a SARTORIUS Miras 2 scales and returned. Based on the obtained weighing results, the current moisture content of dried sea buckthorn berries was calculated:

$$
\omega_{i}=100-\left(\frac{100 \cdot m-\omega \cdot m}{m_{i}}\right),
$$

where $\omega_{i}$ - moisture content of the dried berries at any time during drying, \%;

$m_{i}$ - mass of the sample of dried berries at any time of drying, $\mathrm{kg}$;

$\omega$ - moisture of berries at the beginning of drying, \%;

$m$ - mass of the sample of dried berries at the beginning of drying, $\mathrm{kg}$.

Drying of sea buckthorn berries was continued until the moisture content of the dried berries in the ventilated containers decreased to $13-15 \%$. Drying of the dried berries was then stopped and the ventilated container with the berries was weighed one last time.

\section{Results and discussion}

The initial average moisture content of sea buckthorn berries used in the study was $86.4 \pm 0.37 \%$. It was determined by the reference method by drying the berry sample in a MEMMERT UF450 oven at $105 \pm 2{ }^{\circ} \mathrm{C}$ to constant weight. At that time, drying tests were performed on a drying stand by ventilating the berries with an intensity of $1.25 \pm 0.16 \mathrm{~m} 3 \cdot(\mathrm{h} \cdot \mathrm{kg})-1$ at a temperature of $33.0 \pm 2.3^{\circ} \mathrm{C}$ and a relative humidity of $54.9 \pm 4.6 \%$. In this way, the berries were dried to a moisture content of $13-15 \%$.

Fresh sea buckthorn berries dried the longest without additional heat preparation (Fig. 2). The drying process took 891 hours. Within 37 days, the moisture content of the berries decreased from $86.4 \pm 0.37 \%$ to $13.6 \pm 0.31 \%$. Cold treatment of the berries or high temperature before drying had a significant effect on their drying time. The drying time of frozen berries decreased by 1.31 times. The berries dried to $14.6 \pm 0.34 \%$ in 682 hours. The effect of high-temperature treatment was even more effective: the drying time was reduced by 6.06 times. Sea buckthorn berries, which were stored at $90{ }^{\circ} \mathrm{C}$ for 1 hour before drying, reached a moisture content of $13.5 \pm 0.41 \%$ in 147 hours.

The drying process of fresh berries differed from the classic drying process, which clearly captures the three drying stages. It was a slowly accelerating process. An extremely low but stable drying rate was recorded at the beginning of drying, which lasted about 335 hours. During the day, the moisture content of sea buckthorn berries decreased by only $0.650 \pm 0.178 \%$. Significant changes occurred during the fourth drying period (Fig. 3), 271-360 drying hours. The drying process and drying conditions stabilized. Until the ninth drying period (up to 700 drying hours), the temperature of the drying agent 
flowing from the sea buckthorn layer was the lowest $\left(30.5 \pm 0.45^{\circ} \mathrm{C}\right)$ and the relative humidity was the highest $(68.0 \pm 1.77 \%)$. The drying speed also increased. Until the end of drying, the drying rate of sea buckthorn berries increased exponentially from $0.588 \%$ per day to $8.83 \%$ per day. A relatively intense drying of the berries began and took place, but the quality of the berries was already impaired. The prolonged start of drying created favorable conditions for the appearance of insect larvae in the berries. They were observed in the berry layer after 25 days ( 623 hour, during the seventh drying period) from the start of drying.

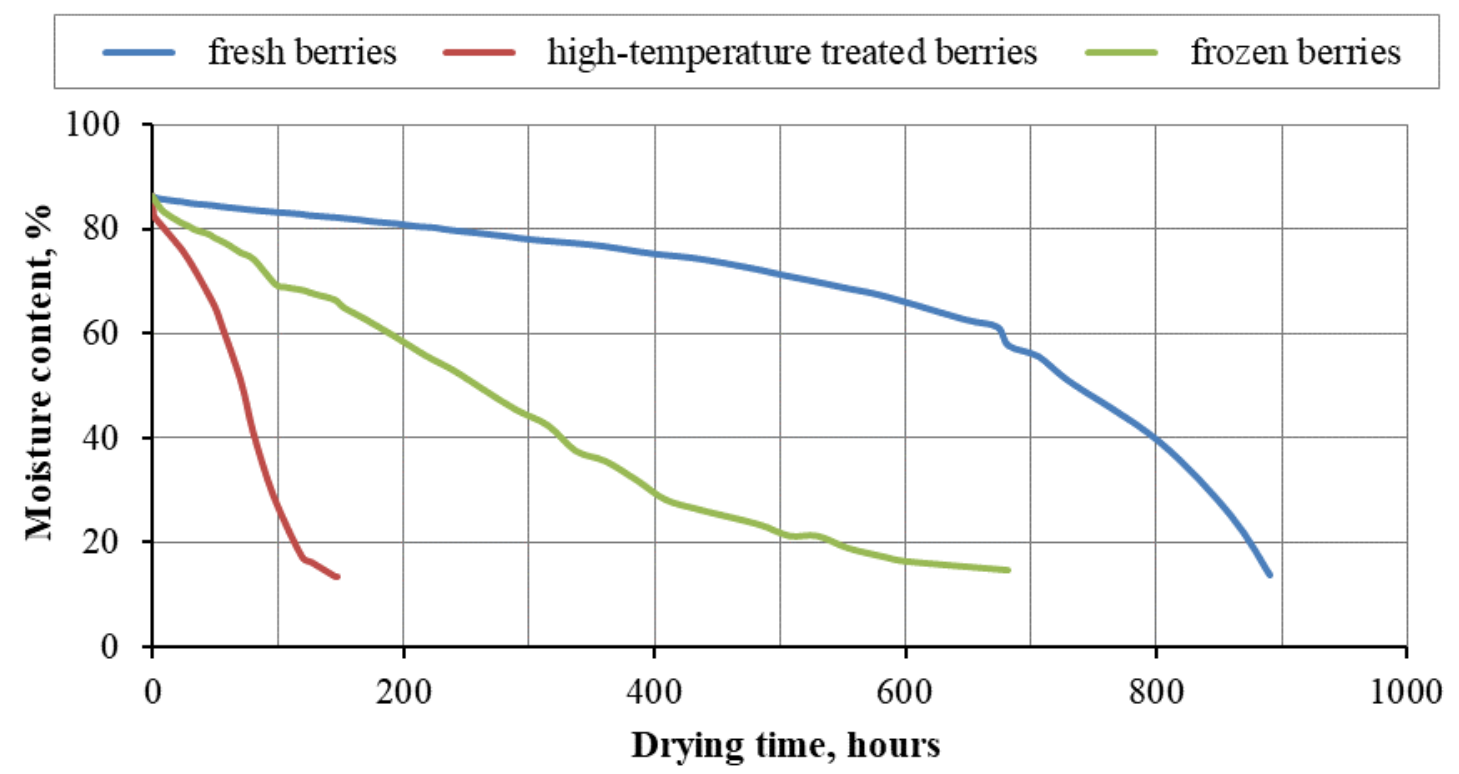

Fig. 2. Drying curves of sea buckthorn berries

The thermal treatment of the berries had a significant effect on the drying kinetics. The drying kinetics of both cold and high-temperature pre-dried berries correspond to the classic drying process, in contrast to the drying kinetics of fresh berries. All three drying stages are recorded.

The first drying stage of frozen sea buckthorn berries lasted only for 10 hours. During it, the berries warmed up and reached the temperature of the drying agent. The berries also lost $3.2 \%$ moisture and dried to $83.2 \%$ moisture. The main drying phase then began, which ended in the seventh drying period (Fig. 3), at 409th drying hour. Fixed period of constant drying rate, which is typical for convection drying technologies. This drying stage of frozen sea buckthorn berries was distinguished by its duration and stability: during it, the drying speed of sea buckthorn berries changed little and was equal to the average value $2.88 \pm 0.786 \%$ per day. Within 399 hours, the berries dried to $28.1 \%$ humidity. Then the drying intensity slowed down. During the tenth drying period (from 585 hours to 650 hours) it decreased 3.3 times and was equal to $0.861 \%$ per day. The temperature of the desiccant flowing through the sea buckthorn berry layer increased to $32.2 \pm 0.428^{\circ} \mathrm{C}$, and the relative humidity decreased to $59.8 \pm 1.236 \%$. The smallest difference from the parameters of the supplied dryer was fixed. Consequently, the drying process was almost non-existent and the moisture content of the berries approached the value of equilibrium moisture.

Part of the fresh sea buckthorn berries were treated with hot air before drying, keeping them in the oven MEMMERT UF450 for 1 hour. During high-temperature processing, the berries lost $3.75 \pm 0.31 \%$ moisture. Thus, the moisture content of high-temperature treated berries at the beginning of drying was lower than in other studies cases. It was $82.6 \pm 0.51 \%$. The temperature of sea buckthorn berries was also higher, $35.0 \pm 0.52{ }^{\circ} \mathrm{C}$. When ventilation began on the drying stand, the sea buckthorn berries were cooled rather than heated. During the first 30 minutes, the dryer temperature dropped to $29.2 \pm 0.29^{\circ} \mathrm{C}$. The beginning of the second stage of the drying process - the stage of constant drying speed was fixed. It was less stable than drying frozen sea buckthorn berries, but 4.11 times more intense. The drying rate of berries varied from $6.87 \%$ per day to $24.0 \%$ per day. In the period from 5 hour to 96 hours, the average drying rate of sea buckthorn berries was $11.84 \pm 5.87 \%$ per day. Consequently, the treatment of fresh 
sea buckthorn berries with hot air had a significant effect on the moisture exchange with the environment during drying.

a)

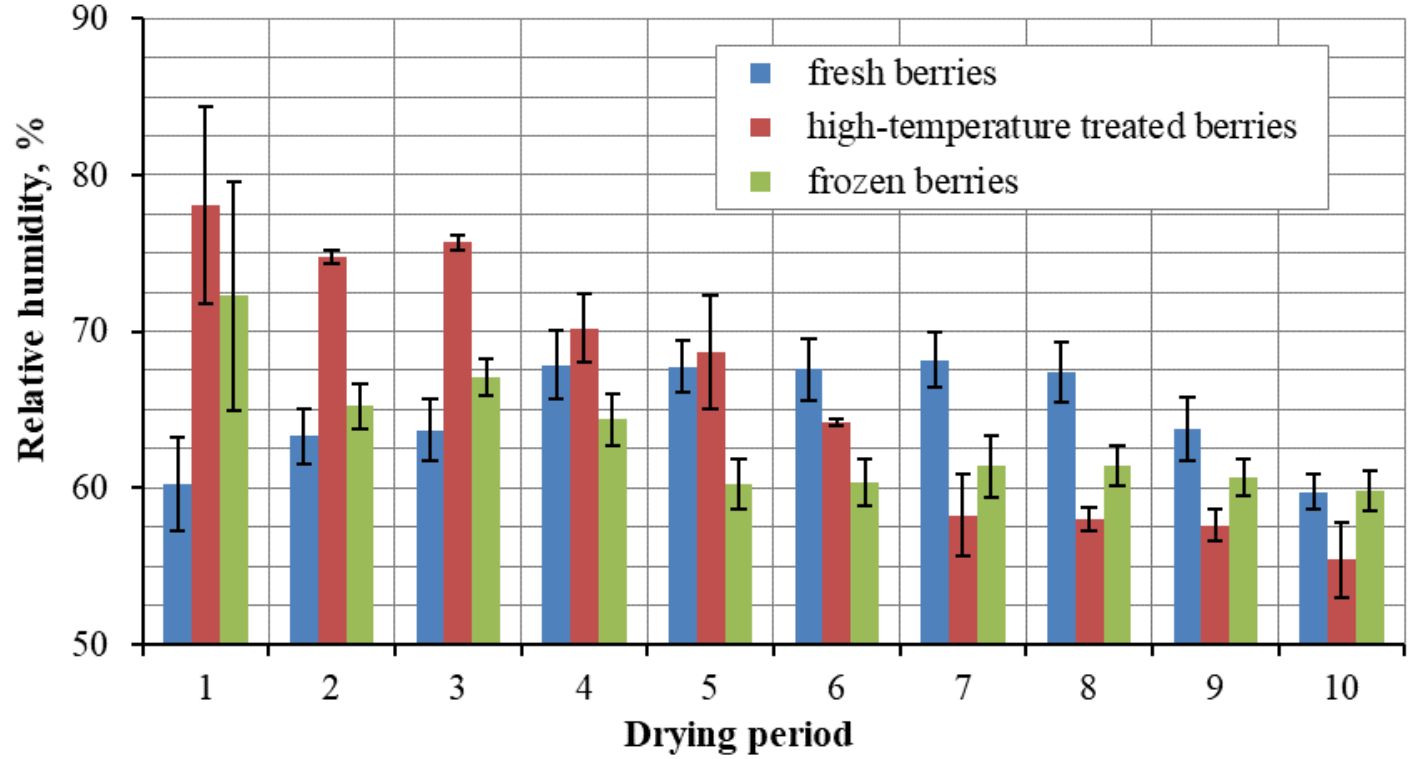

b)

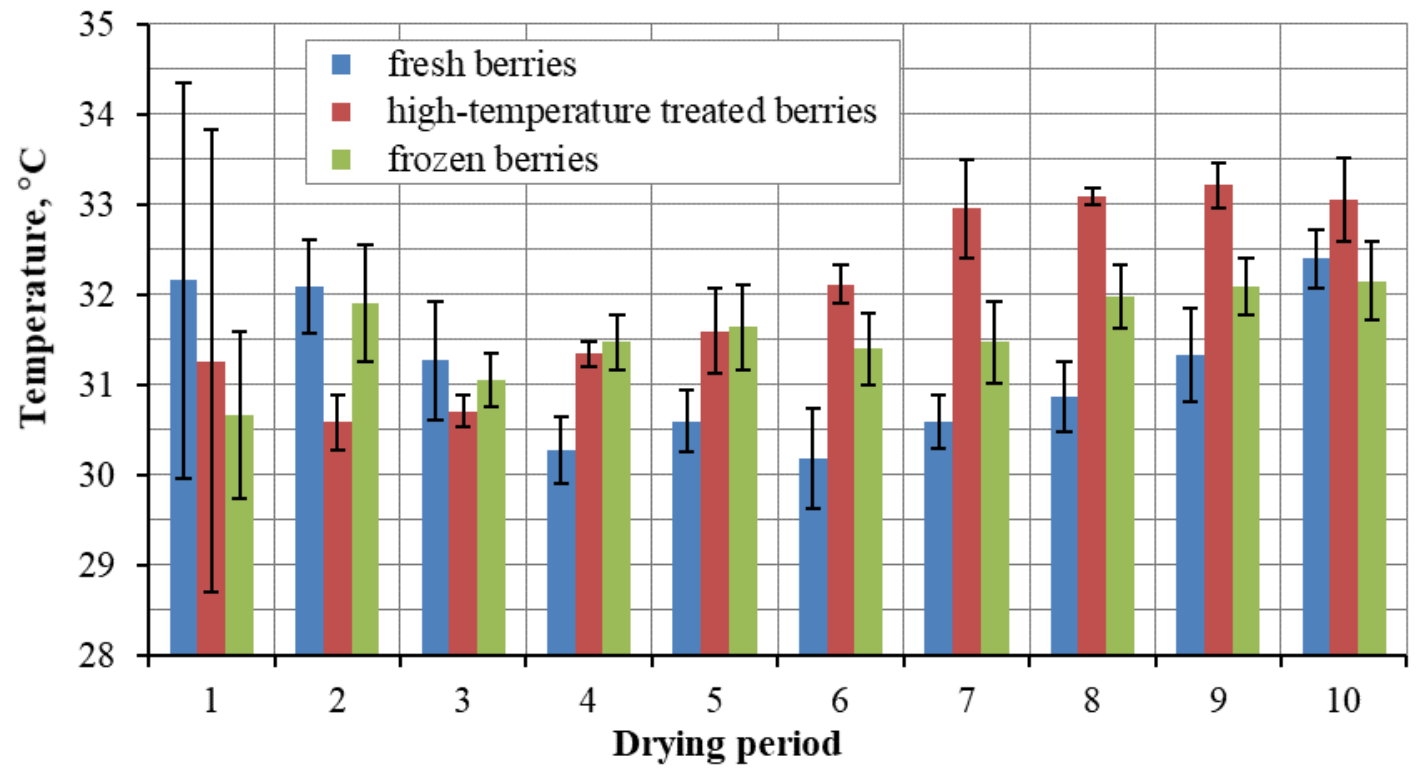

Fig. 3. Parameters of outgoing from a layer of dried sea buckthorn berries: a - relative humidity of the drying agent; $b$ - drying temperature (duration of the drying period for drying fresh berries is 90 hours, for drying high-temperature treated berries -15 hours, for drying frozen berries -60 hours)

In the seventh drying period, the drying rate decreased to $12.34 \%$ per day, and in the tenth drying period it was only $1.108 \%$ per day. A decrease in the relative humidity of the dryer to $57.3 \pm 1.98 \%$ and an increase in its temperature to $33.1 \pm 0.34{ }^{\circ} \mathrm{C}$ also confirm the end of the berry drying process: the moisture content of sea buckthorn berries approached the equilibrium moisture value.

The peel of sea buckthorn berries makes up $7.75 \%$ of the berry weight. It is thick and covered with a layer of wax [8]. This is a very significant factor influencing the drying process. Studies show that thermal treatment of sea buckthorn berries before drying is an effective means of accelerating the process of berry dehydration. The method of perforation of the berry peel was particularly effective when the berries were treated with hot air. Compared with the drying process of heat treated berries, high-temperature treatment of sea buckthorn berries increased the drying speed during the second stage by an average of 8.92 times, and reduced the drying time by 6.06 times. 


\section{Conclusions}

1. It was found that fresh sea buckthorn berries are characterized by a slow intensification of up to $8.83 \%$ per day and 891 hours (37 days) drying process, during the ventilated with $33.0 \pm 2.3{ }^{\circ} \mathrm{C}$ temperature, $54.9 \pm 4.6 \%$ relative humidity and $1.25 \pm 0.16 \mathrm{~m} 3 \cdot(\mathrm{h} \cdot \mathrm{kg})-1$ dryer flow, humidity of berries decreased by $72.8 \%$, from $86.4 \pm 0.37 \%$ to $13.6 \pm 0.31 \%$.

2. Heat treatment is an effective means of accelerating the dehydration process of sea buckthorn berries and increasing the drying intensity, which has allowed to reduce the drying time of berries by 6.06 times.

3. It was determined that freezing of fresh sea buckthorn berries to $-18^{\circ} \mathrm{C}$ before drying was found to reduce the drying time by 1.31 times, from 891 hours up to 682 hours, and the drying rate was increased 2.17 times during the main drying stage, to $2.88 \pm 0.786 \%$. per day.

4. It was determined that treatment with fresh sea buckthorn berries at high temperature $\left(90{ }^{\circ} \mathrm{C}\right.$ hot air for 1 hour) before drying reduced the drying time by 6.06 times, from 891 hours until 147 hours, and the drying rate was increased 8.92 times during the main drying step, to $11.83 \pm 5.86 \%$. per day.

\section{Acknowledgements}

The research is supported by project No. 35BVKK-18-1-06620-PR001, which is financed from the EAFRD and the state budget of the Lithuania Republic.

\section{References}

[1] Siro I., Kapolna E., Kapolna B., Lugasi A. Functional food. Product development, marketing and consumer acceptance - a review. Appetite, vol. 51(3), 2008, pp. 456-467.

[2] Galanakis C.M. Functionality of food components and emerging technologies. Foods, vol. 10(1):128, 2021.

[3] Ciesarova Z., Murkovic M., Cejpek K. etc. Why is sea buckthorn (Hippophae rhamnoides L.) so exceptional? A review. Food Research International, vol. 133:109170, 2020.

[4] George S.D.ST., Cenkowski S. The influence of drying on levels of bioactive compounds in pulp/peel oil of sea buckthorn (Hippophae rhamnoides L. ssp. Sinensis) berries. Journal of Food Processing and Preservation, vol. 33, 2009, pp. 91-109.

[5] Ragažinskienè O. Introdukuojamo dygliuotojo šaltalankio morfologinès ir cheminès savybès. (Morphological and chemigal properties of the introduced sea buckthorn). Optimization of ornamental and garden plant assortment, technologies and environment: scientific articles. Dekoratyviưjų ir sodo augalų sortimento, technologijų ir aplinkos optimizavimas: mokslo darbai, Vol. 4(9), 2013, pp. 118-122. (In Lithuanian)

[6] Suryakumar G., Gupta A. Medicinal and therapeutic potential of Sea buckthorn (Hippophae rhamnoides L.). J Ethnopharmacol, vol. 138(2), 2011, pp. 268-278.

[7] WHO monographs on medicinal plants commonly used in the Newly Independent States (NIS)/World Health Organization. [online] [28.03.2021] Available at: https://www.who.int/medicines/areas/traditional/monograph_eng.pdf?ua $=1$

[8] Bal L.M., Meda V., Naik S.N. etc. Sea buckthorn berries: a potential source of valuable nutrients for nutraceuticals and cosmeceuticals. Food Research International, vol. 44(7), 2011, pp. 17181727.

[9] Seglina D., Ruisa S., Krasnova I. etc. Biochemical characterization of seabuckthorn (Hippophae rhamnoides L.) grown in Latvia. Proceedings of the 3rd International Seabuckthorn Association Conference, August 12-16, 2007, Québec City, Québec, Canada, pp. 159-168.

[10] Singh V. Free radicals, diseases, anti-oxidants and anti-oxidant properties of seabuckthorn (Hippophae rhamnoides L.)/Seabuckthorn (Hippophae L.): a multipurpose wonder plant. Vol. 2. New Delhi, India: Daya Publishing House, 2008, pp. 3-69.

[11] Ratti C. Hot air and freeze-drying of high-value foods: a review. Journal of Food Engineering, vol. 49, 2001, pp. 311-319.

[12] Araya-Farias M., Makhlouf J., Ratti C. Drying of seabuckthorn (Hippophae rhamnoides L.) berry: impact of dehydration methods on kinetics and quality. Drying Technology, vol. 29(3), 2011, pp. 351-359. 